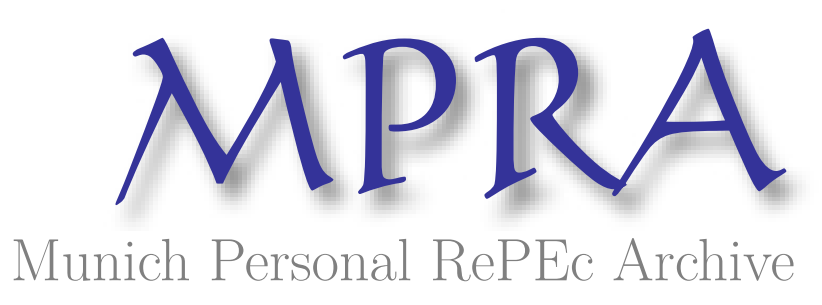

\title{
Measures of income inequality are biased or misinterpreted
}

Kitov, Ivan

IDG RAS

1 November 2014

Online at https://mpra.ub.uni-muenchen.de/59623/

MPRA Paper No. 59623, posted 01 Nov 2014 12:22 UTC 


\title{
Measures of income inequality are biased or misinterpreted
}

\author{
Ivan O. Kitov
}

Russian Academy of Sciences

\begin{abstract}
Considering various measures of personal income and the evolution of the household size distribution we reveal major quantitative inconsistencies in the definition of household inequality. The changing composition of households in the U.S. is the only effect causing the observed increase in Gini coefficient since 1967. When corrected for the actual decrease in the average household size the relevant Gini returns to that of personal incomes. The latter has been hovering in a very narrow range between 0.50 and 0.51 since 1974 .
\end{abstract}




\section{Introduction}

There are several major agencies reporting various measures of personal income in the USA. The Census Bureau (CB) measures personal incomes in household surveys (CPS ASEC) at an annual rate $(\mathrm{CB}, 2006)$. This measure is called Money Income (MI) and includes a variety of personal income sources. The CB provides these estimates to the Bureau of Labor Statistics, also in form of personal/household/family distributions. The Bureau of Economic Analysis (BEA) carries out annual estimates of gross personal income (GPI) as based on administrative records, censuses, and similar surveys, but it does not provide any income distributions (BEA, 2012). In that sense the BEA reports only the aggregate income figure and does not allow inferring the evolution of personal or household income distribution in time. The most important similarities and differences of the $\mathrm{CB}$ and BEA measures are discussed in depth in (CB, 2012). The Internal Revenue Service (IRS) also measures and reports personal incomes filed for tax purposes. Since 1996, the IRS has been publishing detailed tables of personal incomes distribution is various income bins (IRS, 2012). This is similar but somewhat different from the CB's reports.

From the point of view of scientific methodology, different purposes and agencies reporting personal incomes make it difficult to follow up the actual evolution of income distribution and income inequality in the US in quantitative terms. There is no unique personal income definition. Therefore, there is no way to merge all data in one consistent table, to estimate the distribution of income over age/race/sex, and to calculate any quantitative measure of inequality like the Gini coefficient or the Theil index. We illustrate these difficulties with two plots. Figure 1 shows the portion of personal income in nominal GDP as reported by three agencies. The BEA reports around $85 \%$ of GDP as personal incomes but does not include capital gains. The CB and IRS both report only $55 \%$ to $62 \%$ of the GDP as personal incomes while having large differences in income sources.

Since the BEA provides no population estimates as related to its measures of personal income Figure 2 shows two proportions of population with income as defined by the $\mathrm{CB}$ and IRS. The difference of $30 \%$ between these agencies is a dramatic one. In other words, the IRS does not count as personal those incomes which 30 per cent of the total population defines as money income. These incomes ignored by the IRS are generally small and might produce only a small difference in the total personal income.

One may conclude that the way these three major agencies consider and resolve the problem of personal income and income inequality is counterproductive and confusing for any quantitative analysis. This also means that the speculations about income inequality involve different and varying without any control portions of the total income and population. Thus, these speculations are qualitative because no of the involved quantities are compatible in definitions, measuring procedures, and over time. There is an inequality theme, which is full of intentionally biased numbers, however. This is the increasing inequality in incomes of household and families - the main topic of this study.

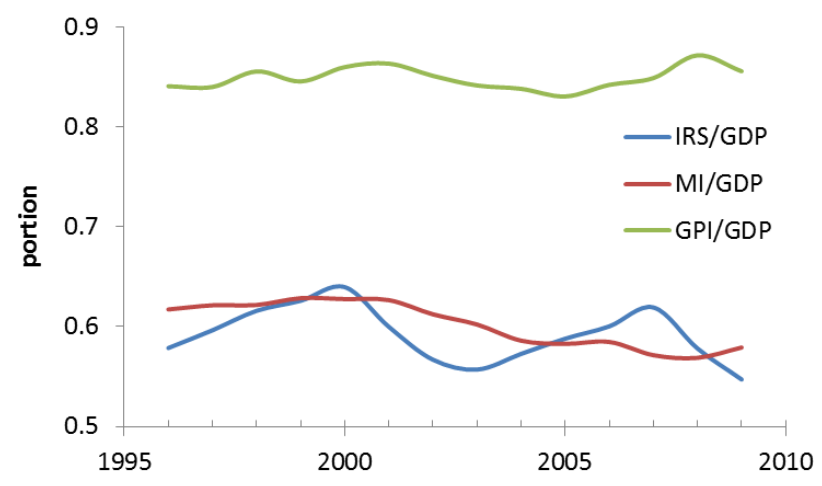


Figure 1. Portion of personal income in GDP.

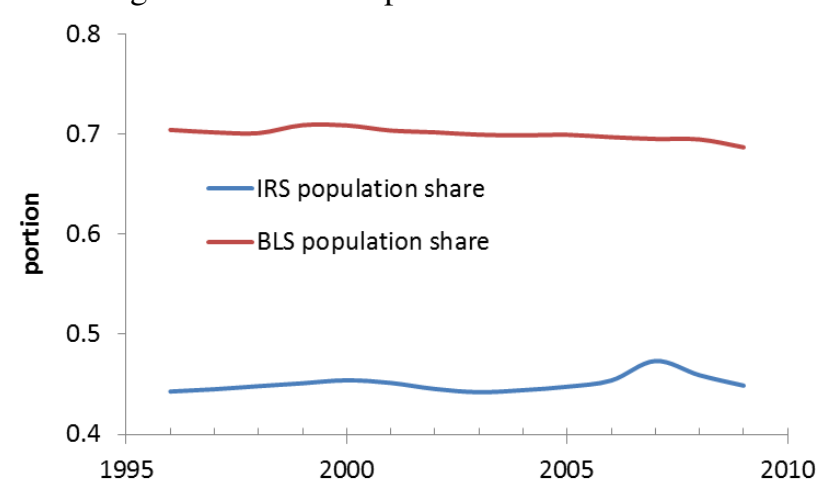

Figure 2. Portion of people with personal income in total population.

\section{The Census Bureau}

\subsection{Personal income inequality}

When discussing the increase in income inequality economists forget those people who have no income at all. According to the Census Bureau, there are tens of millions reporting no income every year and this number has been really growing since 1990 as Figure 3a shows. Notice also the dramatic fall in 1978, which was caused by the largest revision to income definition. More than $15,000,000$ were added to income gainers in a few seconds.

a)

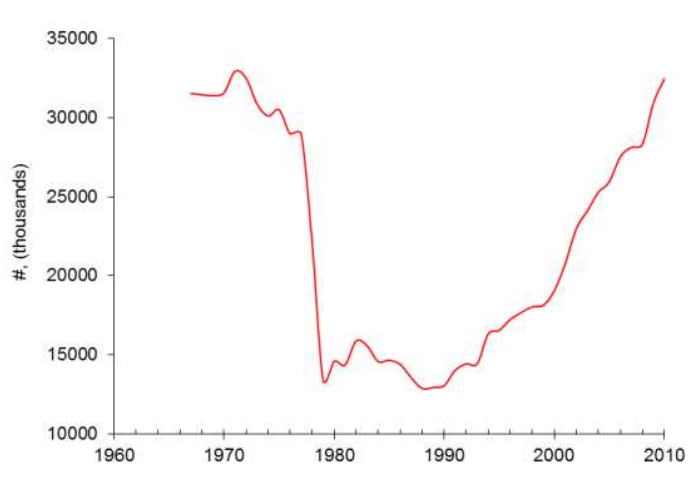

b)

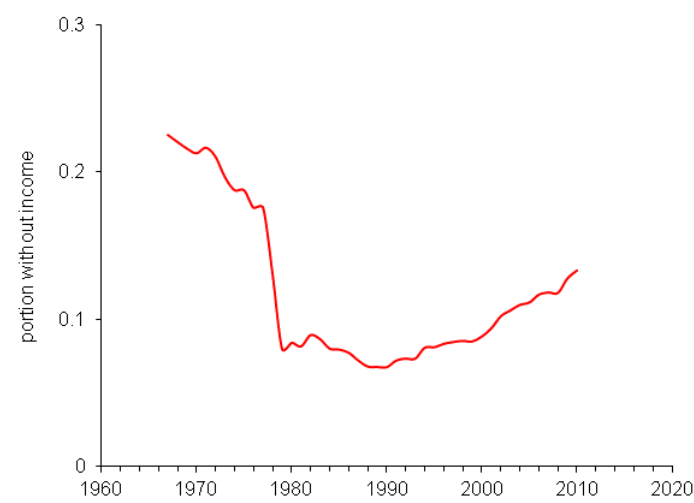

Figure 3. The number (a) and the portion (b) of people without income according to the Census Bureau's definition.

The total population has been also growing by approximately $1 \%$ per year. Figure $3 b$ depicts the ratio of the number of people without income and the total working age population (15 years of age and over). This ratio has been growing since 1990 as well and there was no specific acceleration after 2007. It is not clear why these people are excluded by the Census Bureau from the reported measure of income inequality in the U.S. - the Gini ratio.

Figure 4 displays three estimates of the Gini ratio. Black line presents the estimates published by the Census Bureau which are obtained for people with income only. Red line shows our estimates obtained from personal income distributions (PID) published by the Census Bureau. The difference with the official figures between 1998 and 2011 is 0.011 . This difference is likely related by the fact that we introduced a more accurate approximation of the PID in the lower and higher income bins. In any case, this difference is constant and negligible - 
one may correct any of the estimates by 0.011 and compensate the gap. Therefore, we can use our method to estimate the Gini ratio and apply it to the PID including those without income.

When more than 30,000,000 people with zero income are added one should expect a dramatic increase in Gini ratio. Essentially, thirteen per cent of working population adds to zero income what shifts the Lorenz curve further from the bisecting line. Blue line shows the estimates of Gini ratio for the whole working age population. Unlike the red line, the blue line has been rising since 1990. The period after 2007 is characterized by an accelerated growth, which is obviously associated with the increasing number of zero-incomers. For people with income, the Gini ratio is rock solid over the whole period between 1967 and 2011 (with an almost negligible negative trend). Interestingly, there is no sign of the revision to income definition in 1977. Despite those 15,000,000 who were added in 1978 likely had negligible incomes they did not change the overall personal income distribution. This effect deserves a detailed investigation.

In terms counting, this is a mistake to neglect a substantial part of a closed system when calculating aggregate variables. Such aggregates are intrinsically biased and cannot characterize the system and its behaviour. Currently, the personal income inequality in the U.S. is much higher than the Census Bureau reports: the Gini ratio is rather 0.58.

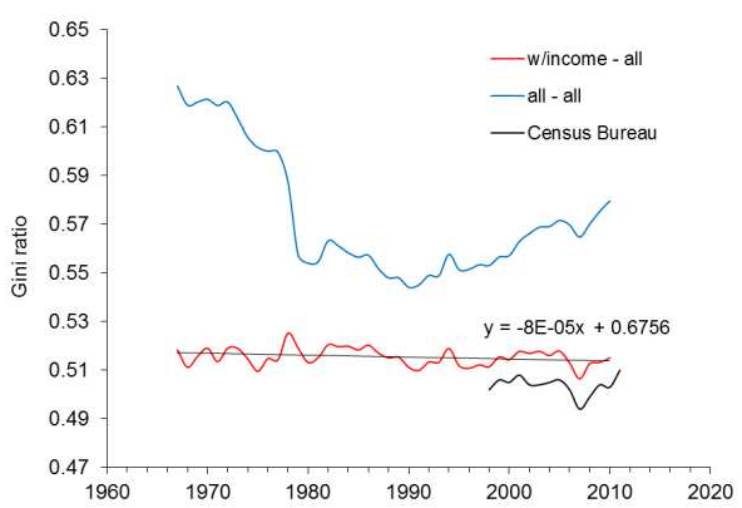

Figure 4. Three estimates of Gini ratio as described in the text.

\subsection{Income inequality for households}

The Census Bureau measures incomes and reports figures. There is general mood of disaster in the growing inequality. Let's try to dig into raw data and find the reason for the observed tendency. Our first point is that the Gini ratio (the most famous measure of inequality) for personal incomes reported by the Census Bureau from the very same data set (CPS ASEC conducted every March) does not change much since 1994. Figure 4 reproduces the Gini ratio, which varies in a relatively narrow range since the 1960s. In Figure 5, we present an exciting and sad history for the Gini ratio for households. We intentionally normalized the ratio to its maximum value $(0.477$ in 2011$)$ in order to show that this inequality measure has risen by $20 \%$ since 1967. This dramatic increase is interpreted as harm for the US.

Unlike personal incomes, the household data are collected for entities which can evolve in size. (A person always has a unit size.) The Census Bureau does not explicitly reports the distribution household sizes and one has to make an own estimate, which is easy, however. Figure 6 presents the total household population (different from civil population or residential population) and the number of households reported by the CB. Figure 7 depicts the evolution of the average household size since 1967. Actually, it was quite spectacular: from 3.2 in 1967 to 2.49 in 2011 . 


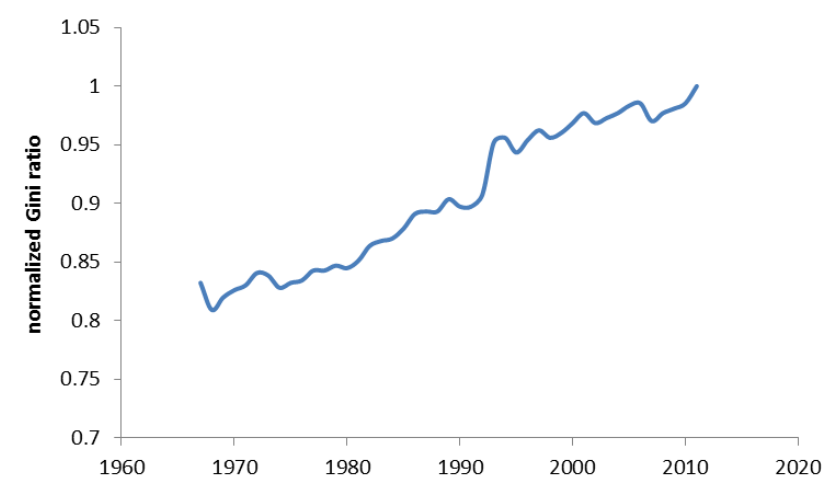

Figure 5. The evolution of normalized Gini ratio for households.

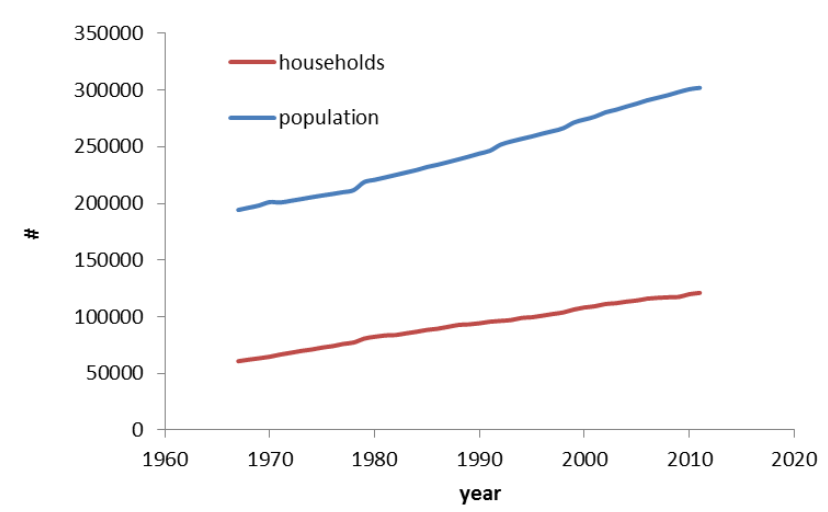

Figure 6. The evolution of total household population and the number of households (both in thousands)

Does it matter for the income inequality? The simplest effect is household split - instead of one big household one gets two smaller households. The Gini ratio depends of the distribution of sizes. The increasing number of households (split) for a given total income results in a higher Gini ratio. When all households are split to the smallest possible number of persons (one) we have the personal income distribution with larger Gini!

So, the current fall in the average size indicates that one gets more and more small households over time and ... the Gini ratio increases accordingly. There is no linear link between the average size and the Gini ratio but Figure 8 shows the product of the Gini curve for households (Figure 5) and the curve in Figure 7. Now we see a corrected Gini ratio history. This corrected Gini ratio is not fully compensated for the household size but tells a different story to the educated audience: the Gini for households has not been changing since the 1970s. In 1993, there was another dramatic revision to income definition and all series were subject to changes. This observed step is artificial.

Overall, the Gini ratio for households has not been changing as the CB estimate say because these estimates do not take into account the change in household size distribution. This is a methodological error. The same logic must be applied to family income distribution - also biased. The mean (and thus median) income estimates also suffer this mistaken procedure. Since the size of household has been decreasing the number of households has been growing faster than the total household population. The mean household income must also be corrected for the changing size. Figure 9 shows actual evolution of the mean income (median income is harder to recover). 


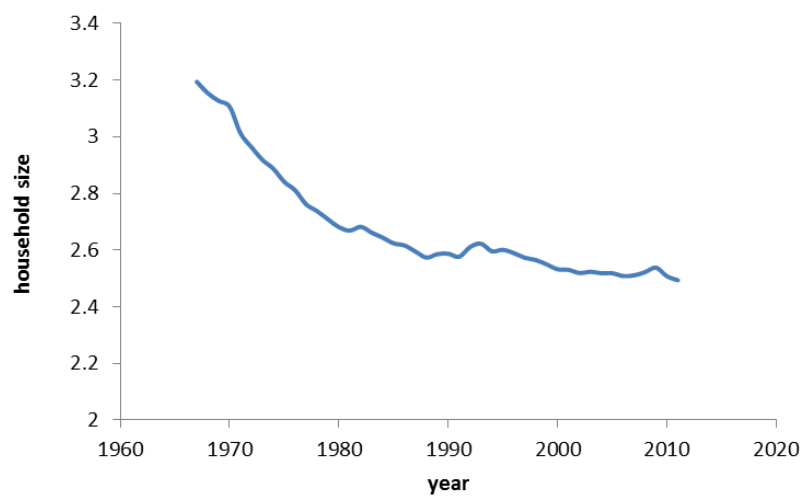

Figure 7. The evolution of an average household size.

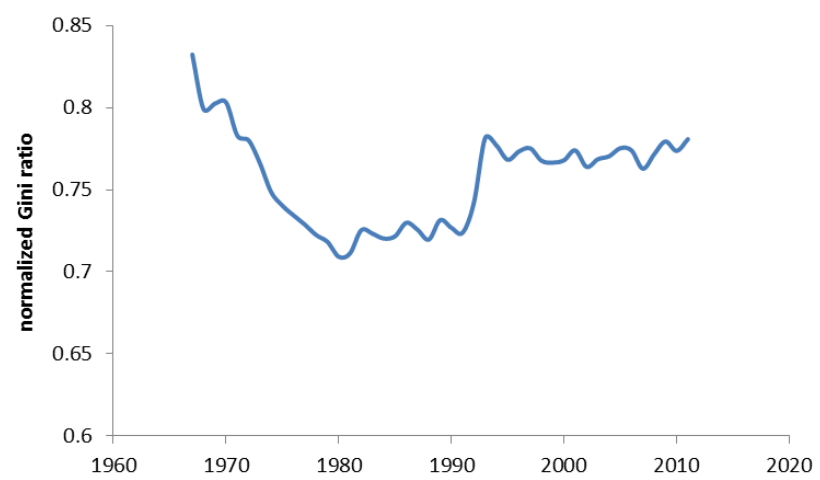

Figure 8. The household Gini ratio corrected for the size of average household.

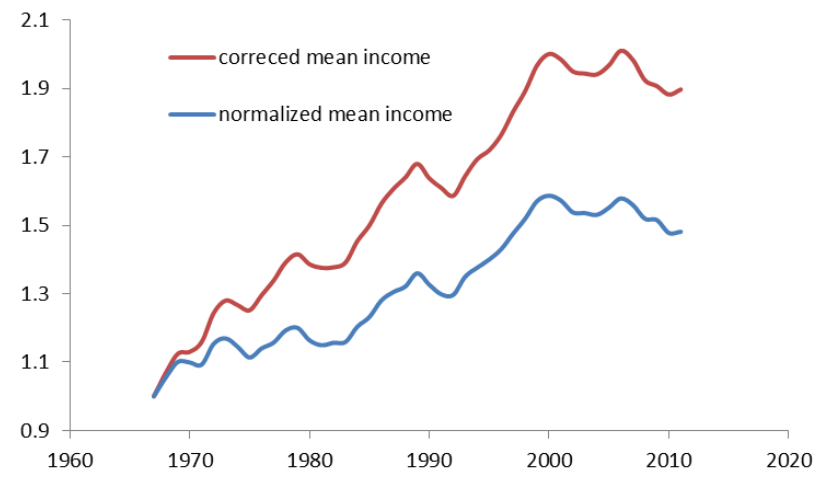

Figure 9. The growth of normalized (household ) mean income and that corrected for the fall in the household average size.

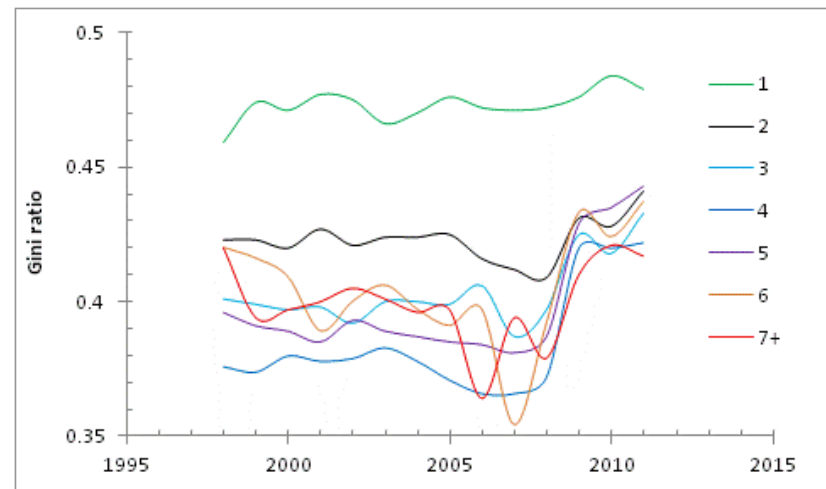

Figure 10. Gini ratio for households of different sizes as reported by the Census Bureau. 
The importance of the household size correction is supported by the Census Bureau, which reports Gini ratio for households of a give size. Figure 10 depicts these CB's estimates, which demonstrate no change at all since 1993, except the one in 2009. (This step is induced by the introduction of new bins in the highest income end.) It is obvious that the change in the distribution of income among all households (e.g. the growth in the overall Gini ratio) must be proportionally mapped into the growing Gini ratio for all household sizes. Richer households should not have any prevailing size. Therefore, the absence of any sign of Gini growth in the households of each and every possible size proves the absence of the overall Gini ratio change since 1993 (at least).

\section{The Bureau of Economic Analysis}

Piketty's book Capital in the Twenty-First Century (2013) attracts common attention and discusses income distribution between labor and capital. The root concern is related to increasing share of capital income, which is also expressed in the growing proportion of total income in the top $1 \%$ of families. Here we are showing that capital does not eat from the part of labor income but converts corporate income into the personal income. The source of increasing income inequality is in the tax law. At the end of the day, US politicians are responsible for the increase in the portion of personal income for the richest families. There are no economic forces behind the change, which would be much more difficult to overcome. We have demonstrated that the proportion of personal (money) income in the Gross Domestic Product has not been changing much since 1947. This is the year when the Bureau of Labor Statistics started to measure personal incomes. The source of some kind of virtual increase in income inequality private companies redistribute their income in favor of personal income of their owners. The question is - how do they get extra money to redistribute to their private owners? The US tax system started to reduce the level of tax for private companies. Primarily, it is made by increasing the rate of depreciation, which enterprises are officially permitted to charge for tax purposes (usually fixed by law).

We start with a graph showing the growth in GDP, gross personal income (GPI) measured by the BEA and compensation of employees (paid) since 1929. Figure 11 demonstrates that the level of GPI has been rising faster than that of the GDP (and the compensation) since 1979. (The share of GPI in the GDP has been rising since 1979!) The difference between the GPI and GDP curves depicted in Figure 12 has a striking kink around 1979. And this is the start of the current rally in the rich families' personal income. In other words, a new political (taxation is a fully political issue) era started in 1979. We would like to stress again the proportion of the compensation of employees in the GDP has not been changing since 1929, with a small positive deviation in the end of 1990s and a negative deviation since 2009. This observation supports our previous finding that the proportion of personal (money) income in the GDP has not been changing.

So, where the extra money is from? The level of personal income has been actually increasing faster than that of the GDP and it should be a looser, which lost its share in the GDP. Figure 13 shows two major components of the GPI. The net operating surplus (private) has been changing at the same rate as the GDP since 1929, while the proportion of taxes on production 
and imports has been growing at lower rate since 1980. We have allocated the source of income for rich families. They take money from the decreasing taxes. But what is the mechanism of money appropriation? Figure 14 demonstrates that the decrease in taxes goes directly into the increasing share of consumption of fixed capital. This is the force behind the increasing income inequality. The increasing share of the consumption of fixed capital is successfully converted in private money, not in investments!

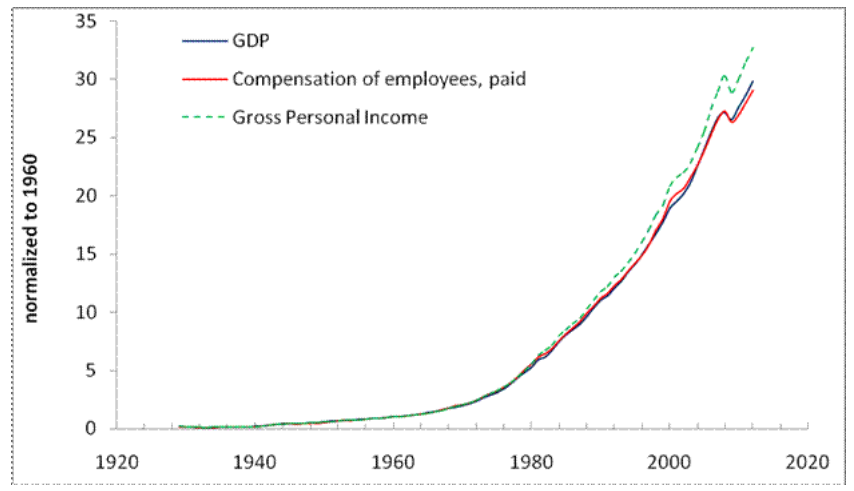

Figure 11. GDP, GPI, and compensation of employees normalized to their respective levels in 1960.

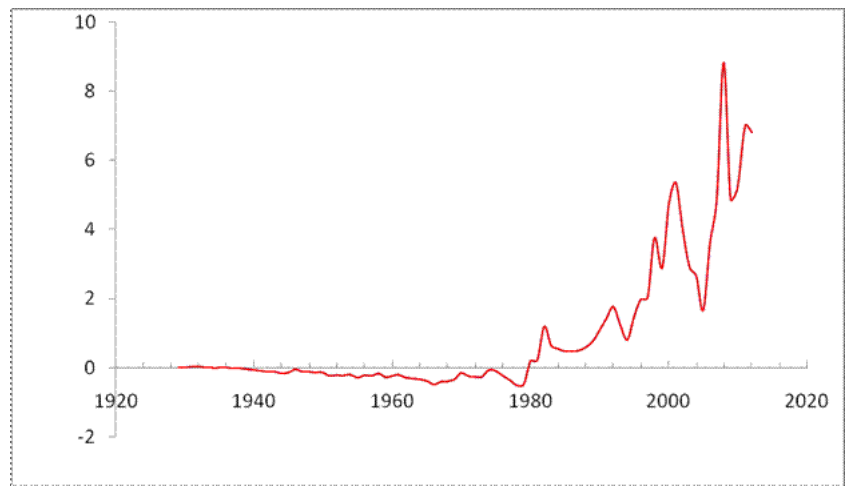

Figure 12. The difference between the GPI and GDP curves in Figure 11.

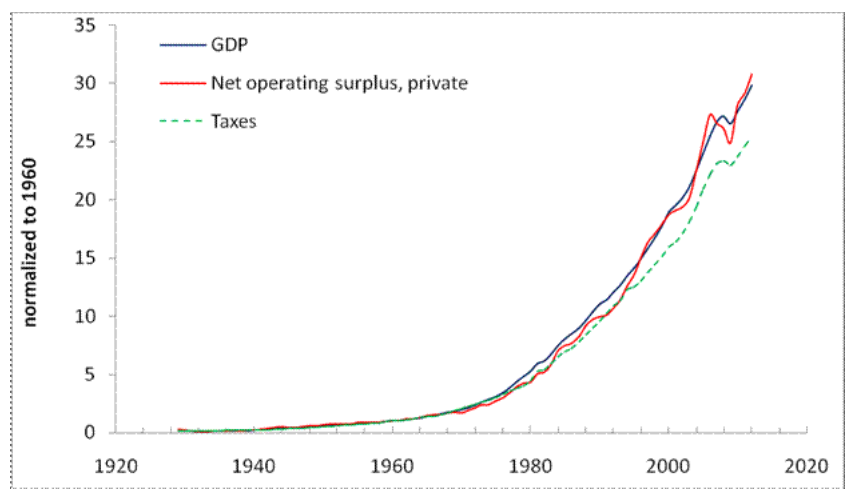

Figure 13. GDP, net operation surplus (private), and taxes (on production and imports) normalized to their respective levels in 1960. 


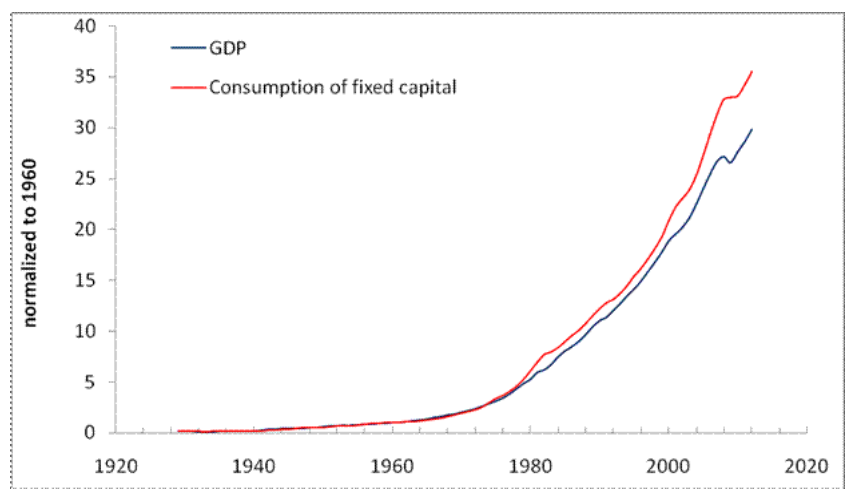

Figure 14. GDP and consumption of fixed capital normalized to their respective levels in 1960

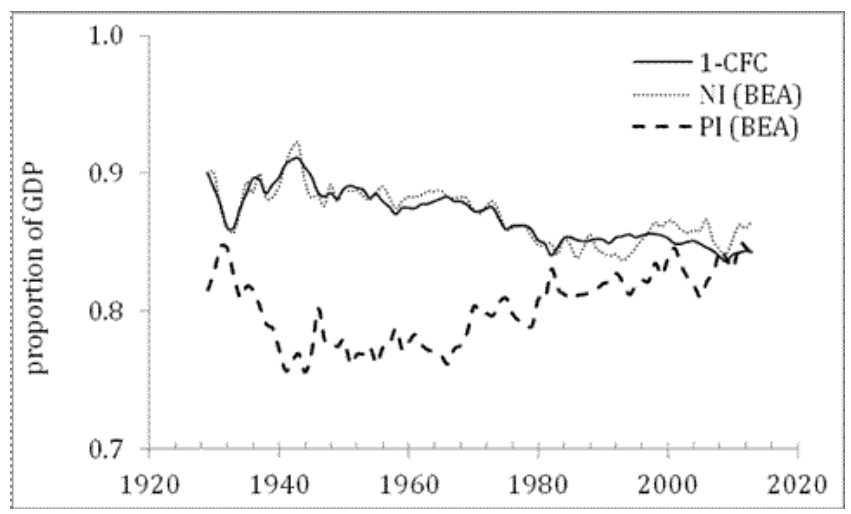

Figure 15. Evolution of national income (NI) and personal income (PI) both normalized to Gross Domestic Product. Currently, they are almost identical.

Piketty projects some further growth in the proportion of capital income. Here we present an extremely simple observation which bans any further growth in the capital's share of income. Figure 15 displays the evolution of national income (NI), i.e. the sum of labor and capital income, and personal income (PI), both reported by the Bureau of Economic Analysis. In the 1970s, the difference was $10 \%$ and then stared to decrease. This is the period which Piketty highlights as the era of capital income, i.e. all increase in the share of personal income was appropriated by capital. Since 2011, there is no room for further growth in the share of capital income - all national income is distributed as personal income. There is no other source of income, except may be decrease in the consumption of fixed capital (CFC). There is nothing to share any more.

\section{References}

Bureau of Economic Analysis (2012). National data. GDP \& Personal Income. US Department of Commerce. Retrieved on December 25, 2012 from http://bea.gov/iTable/index_nipa.cfm 
Census Bureau (2006). Design and Methodology. Current Population Survey. Technical Paper 66, US Department of Commerce, Economics and Statistics Administration. Retrieved on January 01, 2013 from http://www.census.gov/prod/2006pubs/tp-66.pdf

Census Bureau (2012). Comparability of Current Population Survey Income Data with other Data, US Department of Commerce, Economics and Statistics Administration. Retrieved on December 25, 2012 from http://www.census.gov/hhes/www/income/data/comparability/index.html

Internal Revenue Service (2012). SOI Tax Stats - Individual Statistical Tables by Size of Adjusted Gross Income. Retrieved on December 25, 2012 from http://www.irs.gov/uac/SOI-Tax-Stats---Individual-Statistical-Tables-by-Size-ofAdjusted-Gross-Income 